\title{
Confucianismo como humanidad: claves para complementar la modernidad
}

DOI: $10.32870 /$ mycp.v3i9.472

Daniel Lemus Delgado ${ }^{1}$

\section{Resumen}

En este artículo se reflexiona sobre confucianismo y el proyecto de la modernidad occidental. Se afirma que en las Analectas se proponen elementos universales que pueden enriquecer el proyecto de la modernidad. El punto de partida es que las Analectas constituyen un texto abierto que permite un diálogo transcivilizatorio y transtemporal. Por lo tanto, es posible retomar las propuestas confucianas sobre el humanismo y la responsabilidad comunitaria como dos principios básicos para una convivencia universal. El artículo concluye que si somos capaces de reincorporar el humanismo universal confucionista, entonces es posible trascender el exclusivismo modernizador occidental, abriendo nuevos caminos para superar las limitaciones del proyecto moderno.

Palabras clave: modernidad, China, confucianismo, Analectas, civilización china.

\section{Abstract}

In this paper we made a reflection on Confucianism and the project of Western modernity. This paper states that the Analects propose universal elements that can enrich modernity. The starting point is that the Analects are an open text

Artículo recibido el 12 de junio de 2014 y dictaminado el 11 de septiembre de 2014.

1. Profesor-investigador del Centro Asia Pacífico, Tecnológico de Monterrey, Campus Guadalajara, México. Doctor en Relaciones Internacionales Transpacíficas por la Universidad de Colima.

Miembro del Sistema Nacional de Investigadores, candidato. ORCID http://

orcid.org/0000-0003-1002-5319 Correo electrónico: dlemus@itesm.mx 
which allows a trans-civilizational and trans-temporal dialogue. Therefore, it is possible to retake the Confucian proposals of humanism and community responsibility as two basic principles for a universal coexistence. The article concludes that if we can reinstate the Confucian universal humanism, then it is possible to overcome the Western modernizer exclusivism, opening new ways to overcome the limitations of the modernity project.

Keywords: modernity, China, Confucianism, Analects, Chinese civilization.

\section{Las limitaciones de origen de la modernidad y las necesidades de una complementariedad}

En los albores del siglo xxI el mundo se encuentra en una encrucijada. ${ }^{2}$ Por una parte, el proyecto político moderno, siempre imperfecto, inconcluso, etéreo, vago y en apariencia inalcanzable, muestra vicios de agotamiento y desencanto. Por otra, el proyecto económico que ha sustentado la modernidad se muestra eficiente para generar riquezas pero al mismo tiempo, en su implementación, ha sido un proyecto sumamente polarizador. Así se han generado las más profundas desigualdades sociales, y se ha postergado la posibilidad de construir una sociedad más justa e incluyente. ${ }^{3}$ En consecuencia, la sensación generalizada es que debido a la expansión de la misma modernidad y las consecuencias que ha generado, nos encontramos en una nueva era que no es necesariamente más promisoria (Giddens, 1996).

2. El autor de este artículo agradece a los revisores anónimos cuyos comentarios y sugerencias enriquecieron la reflexión sobre el tema.

3. El origen del término "moderno", en su forma latina, fue utilizada por vez primera a finales del siglo $\mathrm{V}$ para diferenciar el presente, ya entonces oficialmente cristiano, del pasado pagano (Habermas, 1995: 131). Desde su origen, la modernidad es, en primer lugar, una toma de conciencia sobre la ruptura con el pasado (Le Goff, 1997). Sin embargo, como afirma Nicolás Casullo (1995: 15), para muchas tesis historiográficas la condición moderna se inicia en el Renacimiento durante los siglos XV y XVI. El problema de definir la modernidad es la polivalencia del concepto: lo mismo hace referencia a un periodo histórico que a un proyecto o a un modelo. Es al mismo tiempo una aspiración, que una concretización espacio-temporal. Para el presente artículo parto de la definición de modernidad propuesta por Ellis, quien la define como: “[...] una condición, mentalidad o síndrome por presentar dilemas característicos de los seres humanos [...] los elementos de la condición moderna incluyen el rechazo de la autoridad tradicional, una noción progresista y no cíclica del tiempo, la emancipación individual y colectiva, una orientación ampliamente empirista hacia la comprensión del mundo, y una perspectiva prometeica que considera a todas las dificultades como problemas técnicos que pueden ser dominados a través de la actividad humana" (Ellis, 2005: 1473). 
La encrucijada aparente que se muestra en nuestro horizonte consiste en el conflicto entre el proyecto político moderno fundamentado en el marco democrático, y la implacable modernización económica. La primera opción nos coloca ante un incremento de las capacidades del Estado en busca de las soluciones políticas a los problemas sociales y la limitación al expansionismo galopante y desenfrenado del modo económico de la modernidad. Mientras que la segunda opción refuerza este expansionismo bajo el supuesto de la eficiencia, la libre competencia, la inventiva y la innovación, y apuesta por el mercado como regulador de las condiciones materiales de la vida en sociedad.

Desde esta perspectiva, la decisión que se tome encaminaría indudablemente a profundizar un tipo específico de modernidad, en contraposición con las formas tradicionales de organización política, económica o social. Pareciera que la única elección posible se sitúa en el terreno de la modernización. No es de extrañar que esta idea sea generalizada, ya que la modernización se presenta a sí misma como una apuesta por el futuro con la esperanza de que, a pesar de todas las vicisitudes del presente, el mañana sea mejor que el ayer. ${ }^{4}$ De esta forma, la lectura en apariencia es sencilla: no hay camino más allá de la modernidad y la solución a nuestros problemas la debemos buscar en su mismo planteamiento.

Es por eso que pensar que encontrar en el pasado elementos que complementen el proyecto moderno puede parecer una actitud ingenua, sin sentido. Es decir, pensar que se pueden atraer desde el pasado algunos elementos no modernos, tradicionales, como posibilidades de rutas distintas por las cuales transitar, alejados de la actual vía en que se encuentra el mundo, se mostraría como algo retrógrado, infecundo, limitador. ${ }^{5}$

4. Esta percepción parte del discurso filosófico de la modernidad que ha generado una concepción espacio-temporal basado en su propia autorrecreación. Al respecto, Marín-Ardilla precisa: "El discurso filosófico de la Modernidad es eurocéntrico, la filosofía de la historia moderna está diseñada de forma tal que sea la Europa Ilustrada y del Progreso la etapa acabada y superior en la escala evolutiva, en procura de la cual todo el pasado trabajó fatigosamente. Las visiones lineales y acumulativas del transcurrir temporal cocinaron la consecución de una Europa iluminada, racional, democrática, industrial, cuya ideología es la unidad del género humano, la creación y protección de los derechos humanos, la realización de la paz y el denodado y triunfante combate contra la barbarie, contra la superstición y la ignorancia. Todo empezó en el siglo XV: mientras el resto del mundo estaba oculto por los halos místicos, los despotismos teocráticos y una autarquía local insulsa, Europa abrió los ojos e inauguró la Era de la Razón, la Era de la Civilización" (Marín-Ardilla, 2009: 246 y 247).

5. En este sentido Viano afirma que el término modernidad asume una localización precisa y tiende a designar el inicio de una nueva era; entonces la modernidad es vista como decadencia y como 
La idea de la modernidad como única ruta posible para la concretización de las aspiraciones humanas es el resultado de un imaginario colectivo sustentado en la propia visión de la historia, que en su versión teleológica propone que el sentido último de la historia es el progreso humano (Callinicos, 1993). ${ }^{6}$ Evidentemente, la construcción de la idea de modernidad no ha recorrido un camino único, exclusivista y eurocéntrico, sino que dentro de la misma modernidad se encuentran otras líneas interpretativas dialogantes con otras tradiciones no modernas. No hay una modernidad sino modernidades. Sin embargo, hasta ahora es la visión de una modernidad eurocéntrica y cerrada la que ha prevalecido. Tal vez el triunfo ideológico más importante del siglo XIX fue el convencimiento generalizado de que el pasado no debía, no podía, proporcionar claves para solucionar los problemas del presente (Le Goff, 1997). La idea del conservadurismo como la expresión más mezquina de la inteligencia humana por su oposición al progreso, fue gradualmente expandida y asimilada. ${ }^{7} \mathrm{El}$ mundo intelectual parecía dividirse en dos bandos: progresistas y conservadores. Los primeros, sirviendo siempre a las causas más nobles de la humanidad; los segundos, dominados por la ambición, la tiranía y la ignorancia. De esta manera, se instaló en el imaginario colectivo una dicotomía infranqueable: buenos y malos, modernos y conservadores.

La idea del cambio fue concebida como una de las más genuinas expresiones de la modernidad. Y entre más veloz fuera este cambio, más pronto alcanzaríamos la gran promesa de la modernidad: el progreso (Córdova, 2000). La razón, el intelecto humano, la tecnología aplicada a los procesos productivos, los descubrimientos de la ciencia, la movilidad social, la democracia, en resumen, los resultados palpables de la modernidad, nos instalarían, tarde o

separación del pasado (Viano, 1995: 179). De allí la imposibilidad de mirar al pasado como una fuente de superación de las contradicciones del presente, de la solución de los problemas actuales.

6. Luhmann observa que cuando la sociedad moderna se autonombra como "moderna", se identifica en referencia con ayuda de una relación de diferencia respecto al pasado, lo cual no constituye en sí ninguna novedad; sin embargo, en el caso de la modernidad: "este retorno no se produce hoy a través de la identificación, sino de la desidentificación, de la diferencia. Lo queramos o no, ya no somos lo que éramos, y ya no volveremos a ser lo que somos" (Luhmann, 1997: 16). Por lo tanto, Luhmann concluye que el problema de la sociedad moderna es la búsqueda de una producción constante de la otredad.

7. En este aspecto, como lo ha señalado Touraine, se termina por naturalizar lo moderno: "El triunfo del progreso culmina necesariamente en esta naturalización de la sociedad en nombre de la cual quienes se oponen a la modernidad y su revolución son considerados obstáculos, elementos antisociales que deben ser suprimidos por los buenos jardineros encargados de extirpar las malas hierbas" (Touraine, 2002: 89). 
temprano, en una nueva tierra prometida. La modernidad era vista esencialmente como el triunfo de la razón, como una auténtica liberación y un camino genuino hacia la revolución como cambio transformador (Touraine, 2002).

La idea de lo moderno como lo deseable se complementó con un tinte de excepcionalidad. Así, se generó la concepción de lo moderno como un fenómeno exclusivamente occidental. La modernidad era posible gracias a la excepcionalidad de la civilización occidental. Más allá de la civilización occidental, se pueden encontrar eventos interesantes, adelantos tecnológicos asombrosos, manifestaciones artísticas sorprendentes y formas de organización política y social originales; ninguna de ellas capaz de gestar en sí misma las particularidades del proyecto moderno (Sardar, 2004). ${ }^{8}$ Las demás civilizaciones y culturas quedaron así condenadas a imitar y seguir la ruta de la modernidad trazada por la civilización occidental. La nueva tragedia no consistía en el estrato social en que uno naciera, como en el mundo medieval, sino en la región del mundo de la cual se fuera originario. Más allá de la Europa Occidental, no se podría alcanzar un auténtico progreso. La solución a esto era obvia: adoptar los valores de la modernidad (Wallerstein, 2007).

La expansión de los proyectos políticos y económicos de la modernidad, y con ello de los valores que los soportan, se ha acelerado en las últimas décadas debido a la globalización. Si bien es cierto que la globalización no es un hecho reciente, dado que las tendencias, dinámicas y propósitos están presentes desde el origen de la modernidad a finales del siglo XV, es un hecho que el motor de esta expansión, determinado por la lógica de la acumulación de capital y el avance tecnológico, ha permitido que hoy en día el proyecto moderno tenga un impacto planetario (Robertson, 1992). La paradoja es que la modernidad no se puede encerrar, bastarse y terminar en un contexto limitado, sino que ha alcanzado una escala mundial. Tarde o temprano, con entusiasmo o con desánimo, los efectos de la modernidad han trastocado las estructuras originales de las diversas comunidades del mundo. Por lo tanto,

8. Al respecto véase Pagden, quien señala: "Si los colonizadores europeos exportaron a América la noción de una civitas, sostenida e impuesta por la visión correlativa de un imperium cristiano, sus descendientes han creado un orden universal basado en otro concepto de civilidad no menos globalizante: la democracia, una ideología expansiva y sin duda tan exigente como sus precedentes fundadas en la Antigüedad y el cristianismo. Al igual que la noción de civitas, la democracia divide al mundo entre quienes viven en su seno y los que quedan al margen de ella. Como la "República Cristiana" de san Agustín, recibe a quienes deseen incorporarse a ella, pero deshumaniza a quienes optan por no hacerlo. Como las dos, es incapaz de concebir la existencia de los otros mundos" (Pagden, 1995: 253). 
los proyectos de la modernidad permean las distintas regiones del planeta. ${ }^{9}$ Se ha generado así la mezcla entre la modernidad, la occidentalización y la globalización como tres fenómenos que confluyen en una misma realidad.

Es por esta razón que nuestras concepciones paradigmáticas de la realidad han limitado las posibilidades de ver, más allá de nuestra visión occidental y nuestra concepción de la historia, elementos que puedan complementar a esta modernidad imperfecta. Sin embargo, la modernidad, por su origen histórico y civilizatorio, no puede abarcar todas las civilizaciones y tradiciones culturales de los grupos humanos. La modernidad, como lo ha señalado Habermas (1995), es un proyecto incompleto e inacabado. Y una de las razones por la cuales es un proyecto incompleto se desprende de su propio origen histórico y geográfico (Marín-Ardila, 2009). Por lo tanto, si queremos complementar la modernidad para que pueda ser un proyecto incluyente, es necesario mirar otros horizontes. Es preciso explorar en el pasado y en contextos civilizatorios diferentes otras propuestas que permitan presentar soluciones distintas a los problemas de hoy.

Si partimos del hecho de que la modernidad es un concepto occidental, entonces podemos aceptar que la modernidad como proyecto estará incompleta mientras no sea capaz de incorporar nuevas formas de relacionarse con civilizaciones no occidentales (Wallerstein, 2007). La modernidad, como aspiración universal, debe recuperar otros elementos no europeos para poder caminar hacia la construcción de un modelo realmente universal. En este sentido, la modernidad sólo estará completa como proyecto cuando sea capaz de incorporar elementos más allá de sus fronteras temporales y civilizatorias. Nunca encontraremos una genuina solución si partimos desde la oposición dicotómica tradición-modernidad. Antes bien, el camino a recorrer es el de la complementariedad. Es decir, pensar la modernidad como un proyecto que se sustenta por su capacidad de complementariedad y no de exclusión.

Esta posibilidad de una modernidad que complementa y es complementada por otras tradiciones civilizatorias es posible gracias a las propias diná-

9. Berman considera que hoy en día todos los hombres y mujeres del mundo comparten una forma de experiencia vital a la que denomina modernidad. Señala: "Ser modernos es encontrarnos en un medio ambiente que nos promete aventura, poder, alegría, crecimiento, transformación de nosotros mismos y del mundo y que al mismo tiempo amenaza con destruir todo lo que tenemos, lo que sabemos, lo que somos. Los ambientes y las experiencias modernas cruzan todas las fronteras de la geografía y la etnicidad, de la religión y de la ideología; en este sentido, puede decirse que la modernidad une a toda la humanidad" (Berman, 1998: 1). 
micas de la globalización; de una glocalización, que puede permitir un viaje de ida y vuelta, un diálogo profundo y permanente, una dinámica dialéctica entre distintas comunidades mundiales en las que cada una pueda aportar elementos propios para construir un proyecto auténticamente universal. ${ }^{10}$

La propuesta de este artículo es que podemos encontrar algunos elementos para complementar la modernidad si miramos el mundo tradicional chino, particularmente el pensamiento confucionista. China, al igual que el resto del planeta, se encuentra hoy en una encrucijada. El sorprendente avance económico que China experimenta es el resultado, en gran medida, de asumir el proyecto económico moderno. Sin embargo, ahora se manifiesta el rostro oculto y perverso de ese proyecto moderno económicamente exclusivista. La creciente desigualdad al interior de la propia sociedad china, el incontable daño medioambiental, el crecimiento de la sociedad de consumo que rompe los lazos tradicionales de solidaridad comunitaria son consecuencias de esta modernidad económica. El éxito de la modernidad china expresado en la incorporación a los mercados globalizados ha situado a esta nación a ser la segunda economía más grande del planeta. Esta modernización puede ser al mismo tiempo su más estrepitoso fracaso (López, 2012). Los signos preocupantes de este probable colapso se observan por doquier: crecimiento sin igualdad, privilegios basados en la exclusión, nacionalismos xenofóbicos, corrupción sin freno y formas de legitimización autoritarias.

La implementación del proyecto económico moderno también dotó a China de la capacidad de injerencia en el mundo a partir de su poderío económico. Ahora China tiene una mayor participación en el escenario internacional. Lo anterior a tal grado, que el mundo no se puede comprender sin China, como China no se puede comprender sin el mundo (Mitter, 2008). Un mundo en el que la modernidad se ha convertido en el proyecto dominante.

Ante este panorama, propongo que una de las maneras en que China y el mundo pueden moldear la modernidad para que sea un proyecto incluyente,

10. Khondker (2004) ha advertido que la glocalización es la noción que elimina el temor de muchos de que la globalización es como un maremoto que borrará todas las diferencias culturales de los diversos grupos humanos. La glocalización deja a un lado la impresión de que la globalización es una fuerza que crea un mundo uniforme, un mundo donde las barreras desaparecen y las culturas se convierten en un todo global. Desde esta perspectiva, las tensiones y los conflictos entre las culturas no son más que los problemas de una fase transitoria. Irónicamente, la fase de esta supuesta transición ha estado presente por un largo tiempo. Y como nos muestra este siglo XXI, muchos de los viejos problemas derivados de las diferencias de culturas y religiosas permanecen. 
solidario y participativo, a escala planetaria, es preciso que China pueda recuperar de su pasado, particularmente de la tradición confucionista ${ }^{11}$ los elementos de su civilización clásica que enriquezca al proyecto moderno. Por lo tanto, no solamente es posible, sino deseable, pensar que el confucianismo puede aportar elementos a la modernidad.

\section{El confucianismo más allá de estigma o de idealización}

El primer paso para recuperar algunos elementos de la tradición confucionista y el enriquecimiento del proyecto moderno pasa necesariamente por reconocer las aportaciones del confucianismo en su justa dimensión. Esto implica evitar las visiones extremas que han reducido la complejidad del sistema confuciano a una ideología. Estas visiones extremas identifican un estrecho vínculo con el poder para justificar el statu quo de la China tradicional. En consecuencia, en diferentes periodos de la historia china el confucianismo ha sido idealizado o estigmatizado.

En efecto, en los albores del siglo xx el confucianismo fue visto no sólo como un impedimento para alcanzar la modernidad, sino como la razón principal del ocaso de China. El siglo xIX, el siglo de la decadencia y la humillación para el pueblo chino, fue considerado producto de la ambición de las potencias europeas en su frenética expansión por el mundo para obtener nuevos productos y nuevos mercados. Pero también resultado de las propias debilidades internas de China. Estas debilidades fueron atribuidas al pensamiento confucionista que permeaba a la élite burocrática. Las estructuras políticas y económicas de China se sustentaban en un modelo de pensamiento confucionista visto como arcaico, caduco e inoperante. La máxima expresión de este sistema de pensamiento retrógrado era la propia burocracia china, la cual se mostraba a todas luces ineficiente, ambiciosa y corrupta. ${ }^{12}$

11. El confucianismo es un término genérico que no tiene su contraparte en China. Este término hace referencia a una visión del mundo, una ética social, una ideología política, una tradición erudita y una forma de vida. Si bien es una exageración caracterizar la vida y la cultura tradicional china como confucionista, sí se puede afirmar que los valores éticos confucianos han servido como fuente de inspiración y apelación a las interacciones individuales, comunitarias y nacionales del mundo chino (Tu, 1998).

12. El sistema mandarín estuvo vigente hasta el año 1905. Este sistema tuvo su origen en la concepción confucionista de que solamente las personas más capaces eran las que debían ser servidores públicos. Esta capacidad era evaluada mediante un examen respecto al conocimiento de los clásicos confucianos. El examen estatal finalizaba con un ensayo conocido como ensayo de 
El colapso de los Estados del este de Asia, de tradición confucionista, es la prueba palpable, ante el embate de las potencias europeas, de la caducidad del modelo de gobierno inspirado en las ideas de Confucio (孔子). El derrumbe de estos Estados significó que el viejo confucianismo no era lo suficientemente vital para unir las sociedades al nuevo contexto y sobrevivir (Hang, 2011).

Esta percepción fue expresada en 1916 por Chen Duxiu (陈独秀), ${ }^{13}$ quien más tarde sería uno de los fundadores del Partido Comunista Chino. Él expresó:

La economía es el pulso de la vida moderna y el principio fundamental de la producción económica es la independencia del individuo. Su efecto ha penetrado en la ética. En consecuencia, la independencia del individuo en el campo de la ética y la independencia de la propiedad en el campo económico dan testimonio uno del otro [...] En China, el confucianismo ha basado sus enseñanzas sobre normas éticas. Hijos y esposas no poseen ni individualidad ni propiedad personal. Los padres y hermanos mayores crían a sus hijos y hermanos menores y son a su vez apoyados por ellos [...] Confucio vivió en una época feudal. La ética que promovió es la ética de una época feudal. Las costumbres sociales que enseñó e incluso su propio modo de vida fueron enseñanzas y modos de una época feudal. Los propósitos, la ética, las normas sociales, los modos de vida y las instituciones políticas no iban más allá de privilegiar y dar prestigio a unos cuantos gobernantes y aristócratas y nada tenía por aportar a la felicidad de las grandes masas (Chen, en De Bary, 1998: 1 y 2).

las ocho piernas, "mediante el cual el candidato no tenía que demostrar tanto sus conocimientos de estrategia política o el arte de la guerra o de la diplomacia, sino más bien su perfecto dominio de los clásicos confucianos, así como su capacidad de redactar comentarios sobre aquellas obras en estilo rebuscado y esencial a la vez, que sólo el chino literario podía permitir" (Corsi, 2001: 10).

13. Chen provenía de una familia acomodada de Huaining. Chen recibió una educación clásica. En 1896 aprobó el examen de servicio civil en el más bajo nivel, por lo que no pudo obtener un grado más alto. Posteriormente trabajó como editor de distintas revistas y se desempeñó como profesor y decano. Después de la Revolución de 1911, Chen dirigió el Departamento de Educación de Anhui hasta que fue forzado por Yuan Shikai. a huir a Japón en 1913. Aunque simpatizaba con la revolución, Chen se preocupó más por los cambios culturales y sociales que por el cambio político. Fue un defensor de la igualdad, la democracia y la ciencia y denunció el confucianismo. Fue un activo promotor del Movimiento del Cuatro de Mayo, una protesta nacional desatada por la manifestación estudiantil en contra del Tratado de Versalles, a través del cual habían otorgado la provincia de Shandong a Japón. Arrastrado por el movimiento, Chen fue encarcelado por el Gobierno durante casi tres meses. Tras la liberación, renunció y regresó a Shanghai. Allí se convirtió en marxista y fue uno de los fundadores del Partido Comunista (Ch'en Tu-hsiu, 2004). 
El surgimiento del nacionalismo chino en el siglo xx fue en buena medida construido en oposición al mundo clásico chino, sustentado en el pensamiento confucionista. ${ }^{14}$ Por ejemplo, uno de los intelectuales más críticos del pensamiento clásico chino fue Lu Xun (鲁迅), ${ }^{15}$ quien en la revista Nueva Juventud publicó una sátira bajo el título “Diario de un Loco", donde denunció la hipocresía y vacío de las relaciones humanas del mundo chino. Lu señaló que los relatos de la historia china se llenaron de palabras como justicia y virtudes morales, pero que realmente estas palabras encubrían una realidad miserable (Chang, 2001). Al respecto, John K. Fairbank señala:

The "Diary of a Madman", whose protagonist finds between the lines of "benevolence, righteousness, truth, virtue" in his history book two words repeated everywhere: "Eat men". Chinese culture he wrote, was "a culture of serving one's masters, who are triumphant at the cost of the misery of the multitude" (Fairbank, 1992: 284).

De la misma manera, el Gobierno comunista encabezado por Mao Zedong (毛 泽东) consideró que el confucianismo había sido el pilar ideológico que había mantenido a China bajo las sombras del oscurantismo y había perpetuado la desigualdad social generación tras generación. El confucianismo había sido una cosmovisión que, al justificar el orden jerárquico de las relaciones sociales, había favorecido al reducido grupo de la aristocracia terrateniente y había condenado a China a su propia perdición.

Particularmente, durante la Revolución Cultural el confucianismo fue visto como el lastre que impedía la última modernización que China debía experimentar. Mao Zedong expresó:

14. Al respecto, Martin Jacques nos advierte que China, antes de ser un Estado-nación, ha sido una civilización (Jacques, 2009). En este sentido, uno de los pilares de la civilización china, que se expande más allá de la actual República Popular China y tiene su influencia en el este y sudeste asiático, ha sido el pensamiento de Confucio.

15. Lu Xun fue el primer autor en escribir ficción al estilo occidental; además de escribir narraciones de ficción, fue un prolífico ensayista, crítico y teórico literario y traductor. En 1902, Lu Xun fue a Japón a estudiar medicina, pero después de una profunda introspección, decidió dedicarse a la carrera literaria. Junto con su hermano, publicó dos volúmenes de traducciones de cuentos europeos y puso en marcha una revista literaria. A lo largo de sus escritos denunció enérgicamente que China sufría de una profunda decadencia moral y espiritual. Desde su perspectiva, para modernizarse China debería efectuar un esfuerzo heroico si, entre otras cosas, descartara de las relaciones humanas el servilismo, se desapegara de un pasado retrógrado cuyos principios se habían reducido a poco más que farsa vacía y a una piedad filial sin sentido (Coppola, 1999). 
Aquellos que adoran a Confucio y defienden la lectura de los clásicos confucianos permaneciendo con la ética antigua, los ritos antiguos y el pensamiento antiguo contra el nuevo pensamiento [...] como una cultura imperialista y semifeudal que sirven al imperialismo y a las clases feudales, deben ser eliminados (Mao, en Zhang y Schwartz, 1997: 195).

Esta percepción del confucianismo como factor de atraso la encontramos también en el pensamiento de intelectuales occidentales. Tanto Marx como Weber encontraron en la ética sustentada en los valores confucianos elementos que impedían la propia modernización de China. Por ejemplo, para comprender las razones del atraso de China, Weber rastreó el desarrollo político, económico, social y religioso de China en tres hechos: la existencia de una estructura imperial pacífica, la presencia de una burocracia patrimonial y la importancia de los literatos confucianos. A partir de este análisis, Weber concluyó que la principal causa de la ausencia de un capitalismo en China - $-y$, al contrario, su presencia en Occidente - se encontraba en los valores religiosos en los cuales el confucianismo había tenido una influencia notable (Huang, 1994).

Paradójicamente, en su carrera frenética por alcanzar la modernización económica, hoy en día el Gobierno chino ha lanzado una campaña de recuperación del pensamiento de Confucio. ${ }^{16}$ En 1981 se lanzó una campaña que consideró incluir en las clases de civismo algunas de las ideas de Confucio. ${ }^{17}$ En 2005, la renombrada Universidad Renmin, de la ciudad de Beijing, estableció un Colegio de Estudios Nacionales, el cual es más preciso nombrar

16. En 1979, junto con el proceso de apertura económica, la cúpula del Partido Comunista encabezada por Deng Xiaoping, inició un proceso de liberación y apertura al exterior. A la par, se inició un proceso gradual de rehabilitación de los templos y los monasterios y se animó a los académicos a retomar el estudio del confucianismo no como una ideología feudal sino como sistema filosófico legítimo. En 1982 una nueva Constitución fue adoptada, la cual reconocía la libertad de creencias religiosas. Después de la matanza de Tiananmen, el Gobierno consideró que existía un "vacío moral” en la nueva generación china, por lo que impulsó el resurgimiento del confucianismo. En la década de 1990, cientos de libros respecto a Confucio y su doctrina fueron publicados. Esta fiebre confuciana se ha expandido a series de televisión y al cine (Adler, 2011).

17. Continuando con la tradición del Gobierno comunista de llevar a cabo los proyectos de gobierno a través de campañas, las autoridades lanzaron la campaña "Cinco acentos y cuatro puntos de belleza". Esto consistía en "tensión en el decoro, actitud, higiene, disciplina y moral", y la "belleza de la mente, el lenguaje, el comportamiento y el entorno". La campaña fue considerada como un llamado que el Gobierno hizo al pueblo, a los jóvenes en particular, para perfeccionar su mente y sus acciones. La medida tuvo la intención de recuperar la ética china, que había sido amenazada por la Revolución Cultural (1966-1976). En el fondo, la campaña pretendía construir "la civilización espiritual socialista" (Xueying y Xin, 2008). 
como un colegio para el estudio de los clásicos confucianos (Hang, 2011). Finalmente, en la Plaza de Tiananmen, en enero de 2011, fue colocada una estatua de bronce de Confucio a la entrada del Museo Nacional; y aunque fue retirada meses más tarde, ésta constituyó una muestra más del renacimiento confucionista (Jacobs, 2011).

A partir de esta idealización de la China clásica y de su máximo represente, se ha retomado la figura de Confucio como primer maestro. A tal grado que el Gobierno chino decidió dar el nombre de Confucio a los institutos culturales, cuya misión es propagar la historia y la lengua china. Estos institutos están diseminados por todo el mundo, como manifestación de la presencia sigilosa de China y su llamado a la construcción de una sociedad internacional armoniosa (Paradise, 2009). Al interior de la misma China, el renacimiento del confucianismo ha destacado el concepto de armonía como valor supremo, lo cual podría ser perjudicial para los derechos humanos y la libertad de pensamiento, elementos esenciales de cualquier sistema democrático (Peerenboom, 1998).

De hecho, esta idea ha sido retomada más allá de las fronteras chinas, generando el discurso de la excepcionalidad propia de la civilización asiática. Así, Lee Kuan Yew, primer ministro de Singapur, invocó los valores confucianos como centro de los "valores asiáticos" con la intención de justificar la modernización económica sin necesidad de una modernización política. En otras palabras, los valores confucianos fueron empleados como un medio para justificar los regímenes autoritarios del este de Asia. Otros gobiernos autoritarios de la región han apelado a los valores confucianos con el fin de subrayar el supuesto de que los sistemas económicos y políticos que ellos promueven han sido, en muchas formas, superiores a los de Occidente (Hang, 2011).

Hoy en día, al parecer, el discurso oficial en China no tiene como propósito presentar una alternativa al modelo democrático occidental más allá de la propaganda de proponer un modelo de valores "asiático" o "confuciano". Este reduccionismo del pensamiento de Confucio es producto de una manipulación ideológica (Cheng, A., 2011).

El rechazo y negación del pensamiento del confucianismo y su promoción e idealización son dos extremos de una postura derivada de la adecuación del pensamiento confuciano para justificar los intereses propios. Por un lado, la aceptación como justificación de un orden moral superior; por otro, como la personificación de todas las calamidades. Estas dos posturas extremas son visiones distorsionadas; sin embargo, el confucianismo va más allá de estas 
aproximaciones reduccionistas. Como lo ha advertido Yao (2012), el texto de las Analectas, del cual parten las diferentes interpretaciones de las ideas atribuidas a Confucio, no está confinado a las especulaciones intelectuales; al contrario, este texto penetra en todos los aspectos de la cultura y moldea la forma de pensar y vivir de la civilización china.

Hasta ahora, en la búsqueda actual por encontrar una nueva interpretación del confucianismo, el énfasis ha sido puesto en los siguientes aspectos: por un lado, se subraya el confucianismo como fuente de los valores morales; por otro, se destaca como elemento estructural de un modelo de sociedad distinta a Occidente (Smart, 1989). En el primero de los casos, se apela a la idea de un confucianismo no exclusivista, sino abierto a brindar posibilidades de acción más allá de la cultura china; en el segundo caso

El rechazo y negación del pensamiento del confucianismo y su promoción e idealización son dos extremos de una postura derivada de la adecuación del pensamiento confuciano para justificar los intereses propios. Por un lado, la aceptación como justificación de un orden moral superior; por otro, como la personificación de todas las calamidades. Estas dos posturas extremas son visiones distorsionadas; sin embargo, el confucianismo va más allá de estas aproximaciones reduccionistas la interpretación es reduccionista, exclusivista y cerrada, y limita las ideas de Confucio al margen de la civilización china. Por mi parte, sugiero que las aportaciones del confucianismo como complemento a la recuperación del proyecto moderno, sólo son posibles con la reincorporación de algunas de las propuestas de Confucio a nuestra realidad contemporánea desde el plano ético, es decir, como propuesta de valores universales. 


\section{Consideraciones previas para el acercamiento del pensamiento confucionista desde la propuesta de las Analectas}

\section{La idea de retomar algunas de las enseñanzas clásicas de Confucio partiendo} de las Analectas es, antes que nada, un acto de apropiación y de selección desde el presente..$^{18}$ Por lo tanto, propongo partir de cuatro supuestos que nos permitan ubicar la reinterpretación del confucianismo como complemento a la modernidad. ${ }^{19}$ En primer lugar, es necesario considerar que el confucianismo ha sido, al mismo tiempo, un sistema de pensamiento y un corpus ideológico gestado durante más de 2,500 años. Cada generación, en sus propios autos de apropiación y re-creación, retomó, y retoma, las ideas de la escuela confucionista en un acto que permite dotar de sentido y rumbo a la existencia individual y colectiva. ${ }^{20}$ En la tradición China, el confucianismo ha

18. Las Analectas o Lun-Yü son el texto fundacional de las enseñanzas de Confucio. Como la recopilación que es, se trata de un texto que presenta una serie discontinua de afirmaciones breves, diálogos y anécdotas cortas. Consta de 20 capítulos, cada uno con sus diversas secciones. No existe una lógica secuencial a lo largo de cada uno de los capítulos ni entre un capítulo y otro. Eno (2012) describe a las analectas como una antología de pasajes breves que presentan las palabras de Confucio y de sus seguidores. Este libro pudo haber sido escrito en sus orígenes como una colección realizada por los discípulos inmediatos de Confucio poco después de su muerte, hacia el año $479 \mathrm{~d}$. C. Asimismo, señala que a semejanza de los Evangelios, las analectas nos muestran una imagen de Confucio y de sus ideas a través de los distintos puntos de vista de las diferentes ramas de la escuela de pensamiento que él fundó.

19. Evidentemente, la influencia del pensamiento de Confucio ha rebasado las fronteras de la propia China, estableciendo ideas fructíferas en una serie de intelectuales occidentales. Entre ellas destaca la figura del profesor estadounidense John Dewey, quien sostuvo muchos puntos en común con el confucianismo, particularmente la idea de la educación como un medio para construir una mejor sociedad. Es curioso que la presencia de Dewey en China coincidiera con el despertar de la sociedad civil en los incidentes del 4 de mayo de 1919, mientras que los propios intelectuales chinos buscaban caminos originales para la modernización. Así, durante dos años la presencia de Dewey fue una relación enseñanza y aprendizaje, en un proceso dinámico, lo que llevó a Dewey a ser considerado el segundo Confucio. Al respecto, véase la obra de Jessica Ching-sze Wang (Ching-sze Wang, 2007).

20. De hecho, la idea de regresar a las bases del confucianismo como un elemento para superar las contradicciones internas entre el deber ser, propuesto por Confucio, y la manera en que se materializa diariamente, no es nada nueva. Al respecto, tal vez el ejemplo más representativo es el movimiento de Dongli encabezado por Gu Xiancheng, cuyo propósito fue combatir la laxitud moral y la debilidad intelectual que estaban debilitando la administración pública en los últimos años de la dinastía Ming. Así, en 1604 se fundó la Academia Donglin en Wuxi como un centro privado de aprendizaje y discusión filosófica en el que participaron oficiales reales y eruditos, criticando la influencia del budismo y del taoísmo en el pensamiento confucionista. Evidentemente, las críticas generadas por partidarios de esta corriente política generaron múltiples respuestas desde el poder, lo que culminó con una dura represión hacia los participantes del movimiento, llevando al suicido 
sido siempre tanto una filosofía personal de crecimiento interior como una guía ideológica para las acciones del gobierno y el diseño de las instituciones políticas (Cheng, C., 2011). En este sentido, por lo general el confucianismo ha sido utilizado como un recurso legitimador de las estructuras políticas, sociales y económicas de la China clásica, reflejo de la cosmovisión de una sociedad eminentemente agrícola (Fung, 1997). Sin embargo, las Analectas, que son la fuente primaria desde la que se cimentaron las distintas interpretaciones de Confucio, son, en su origen, un texto vivo, abierto a múltiples interpretaciones y, sin embargo, un texto susceptible de ser absorbido y clausurado por un espíritu tradicional que lo impone de manera dogmática y justificadora, como sucedió en la China imperial. ${ }^{21}$

En efecto, las Analectas en sus orígenes manifestaron una apertura innata debido a la autoría colectiva del texto. Las Analectas no son un discurso unificado escrito por Confucio mismo, así como tampoco poseen una noción preconcebida sobre la intención, contenido, forma y estilo. Al ser un libro construido por muchas manos, es difícil afirmar que los recopiladores de las enseñanzas originales de Confucio fueron fieles a su pensamiento y al contexto histórico desde el cual Confucio enseñó. De hecho, la mayor parte de los académicos coinciden en señalar que los capítulos de las Analectas provienen de distintas épocas y de diferentes fuentes ( $\mathrm{Gu}, 2010)$.

Segundo, es necesario tener presente que las Analectas son una recopilación carente de una estructura lógica-formal a la manera de las propuestas éticas occidentales. Desde su origen, el pensamiento de Confucio ha estado abierto a múltiples significados. Al elegir uno, siempre se niega otro. Sin embargo, se puede afirmar que el origen del texto fue la búsqueda de una solución política al caos imperante de su tiempo. Confucio pretendió generar un sistema ético que diera respuestas a los desafíos políticos. Como cualquier otro programa político, retoma y concluye, desafía y justifica.

a Yang Lian, quien era el principal líder del movimiento, en el año 1627, finalizando prácticamente así esta búsqueda por la reinterpretación y adecuación del pensamiento de Confucio (Donglin, 2014).

21. En realidad esta actitud no es del todo nueva. Simon Leys precisa que en la época de la China dinástica la élite burocrática adoptó de Confucio aquellos elementos útiles para ejercer el poder, para garantizar la sumisión a las autoridades establecidas, "[...] ignorando oportunamente los conceptos más esenciales, como los preceptos sobre justicia social, la disensión política y la obligación moral de los intelectuales de criticar a los gobernantes (incluso a riesgo de su vida), cuando éste abusaba de su poder o cuando oprimía al pueblo" (Leys, 1998: 16). 
En este sentido, las Analectas, más allá de su particular redacción, recogen las enseñanzas atribuidas a Confucio. Tradicionalmente la vida de Confucio se ubica entre los años 551-479 a. C(Slingerland, 2008). Confucio pertenecía a la escuela de los letrados, quienes, en la medida en que se transformaba el orden político y económico de la dinastía Zhou, surgieron como administradores, consejeros, escribas y conocedores de los ritos. Los letrados desempeñaban sus labores en las múltiples cortes, las cuales se expandían en la medida que se fragmentaba el antiguo poder centralizado (Botton, 2000). En este contexto, la época en que Confucio vivió fue un periodo perturbador, ya que el orden social y moral se estaba derrumbando. Como en el caso de Platón, el pensamiento de Confucio se explica a partir de la desintegración de su sociedad y la crisis del orden político (Cheng, A. 2011). De esta manera, la inquietud original de la reflexión ética realizada por Confucio fue encontrar una solución de política a los problemas de su tiempo y propuso como solución la enseñanza de las virtudes éticas para superar el periodo de caos de la época.

La concepción de las virtudes en las Analectas se muestra en dos diferentes niveles. En el primer nivel se encuentra el ren (仁) (humanidad o benevolencia) enmarcado en los conceptos de (德) (virtud) y dao (道) (camino). La importancia de estos conceptos no depende del número de veces que aparecen en el texto, sino que son puntos fundamentales en los cuales las enseñanzas confucianas convergen. Por su significado, pretenden ser universales, en el sentido de que estas concepciones son aplicables a todas las situaciones y a todas las personas. Las tres son consideradas holísticamente, por lo que no pueden ser separadas, no pueden ser jerarquizadas y son mutuamente contenidas e intercambiables. Debajo de este primer nivel se encuentra un segundo nivel de virtudes como zhong (忠) (lealtad), xiao (孝) (piedad filial), gong (恭) (respetuosidad), xin (恭) (veracidad) y yong (恭) (valentía). El hecho de que sean consideradas virtudes de segundo nivel no significa que sean menos importantes, sino porque son tratadas como aplicaciones y extensiones del primer nivel (Yao, 2012).

El hecho de apelar a un orden moral basado en virtudes algunas de las cuales estaban profundamente relacionadas con antiguas prácticas rituales, ha generado diferentes interpretaciones sobre el rol de Confucio en la sociedad agraria a la que perteneció, a grado tal, incluso, que en algunas ocasiones haya sido considerado más un hombre religioso que un filósofo preocupado por las cuestiones políticas de su época. Sin embargo, como lo ha señalado Julia Ching, Confucio puede ser considerado como un humanista abierto a los 
valores religiosos (Ching, 1993). En este sentido, desde la modernidad existe una aparente contradicción entre el mundo secular y el religioso; no obstante, esta diferenciación es más producto de nuestro tiempo y nuestra civilización, por lo cual afirmo que se puede retomar el espíritu secular de Confucio, el cual no es desacreditado por su cosmovisión, que tiene a la vez tintes religiosos.

Tercero, el mismo Confucio se consideraba como un continuador de la historia. ${ }^{22}$ Es en el pasado en donde Confucio encuentra las soluciones a los problemas de su presente. Confucio se apropia del pasado mítico, dorado, de China a través de la lectura de una serie de textos que, con el tiempo, fueron conocidos como clásicos confucianos (Corsi, 2001). El primero de estos libros fue el Yijing (易经) (libro de los cambios), un manual de adivinación atribuido primordialmente al mítico héroe Fuxi (伏羲). El segundo texto, el Shijing ( 诗经) (libro de las odas) es una colección de poemas o canciones, incluyendo lo mismo canciones folclóricas e himnos aristocráticos celebrando a héroes y fundadores de las primeras dinastías chinas. El tercer texto, Shujing (书经) (libro de los documentos) es una colección de declaraciones oficiales y documentos de las dinastías Xia (夏), Shang (商) y Zhou (周) y contiene algunos de los primeros mitos chinos concernientes a los primeros reyes y emperadores. El cuarto libro Qunqiu (春秋) (Anales de las Primaveras y los Otoños) es la cronología de los eventos políticos del Estado de $\mathrm{Lu}$, del cual era originario Confucio. El último de estos textos, el Liji (礼记) (libro de los ritos), describe los rituales de las cortes de la dinastía Zhou, así como comportamientos, tradiciones, vestimentas y otros aspectos de la vida de los primeros reyes de China (Adler, 2012).

Confucio retoma la visión cíclica de la historia. Al mismo tiempo, esta apropiación del pasado es una idealización del mismo. De la lectura del pasado, Confucio deduce que el periodo de caos que él vivía se derivó del desapego a las tradiciones, costumbres, ritos y comportamientos que los primeros gobernantes de China practicaban. Todos los aspectos positivos de la civilización china tenían su origen en el comportamiento virtuoso de los primeros gobernantes, a quienes era preciso imitar (Slingerland, 2008). ${ }^{23}$

22. En las Analectas encontramos la siguiente expresión: "El maestro dijo: Transmito, no invento. Siento confianza y querencia hacia la Antigüedad" (Analectas, 7:1).

23. Entre estos primeros gobernantes destacaban Fuxi (domesticador de animales), quien inventó instrumentos para la caza y la pesca; Shennong (granjero divino), a quien se le atribuía la invención de la agricultura, y Huangdi (el emperador amarillo), inventor de la escritura y la seda. Además, 
Por lo tanto, la manera en que Confucio pretendió encontrar una solución al caos fue por medio de la formación de un funcionario ideal, el junzi (君 子), una persona ejemplar, un caballero. Originalmente el concepto de junzi hacía referencia a un hijo de príncipe, era una categoría hereditaria, pero con Confucio se transforma en una categoría ética, la cual se alcanza por medio del crecimiento interior, a partir de la lectura de los clásicos, como resultado de un esfuerzo individual (Cheng, A., 2011). El junzi es aquella persona capaz de vivir las virtudes confucianas sin esperar recompensa alguna, viviendo en perfecta armonía con el cosmos y con la sociedad. De esta manera Confucio transforma la idea de junzi, al pasar de la concepción original de aquella persona que pertenecía a una élite social, a un nuevo ser humano que pertenece a una élite moral (Leys, 1998). ${ }^{24}$

Evidentemente esta lectura que Confucio hace del pasado es parcial y subjetiva. En consecuencia, no es de extrañar que a pesar de los esfuerzos de objetividad que cada uno emplea, cualquier aproximación del pasado no se pueda desprender de un fin legitimador ni de una apreciación idealizada o desmitificada, con menor o mayor intensidad, pero siempre presente. Mi propósito es presentar algunos elementos que hoy consideramos parte de la ética confucionista, como pretexto para dialogar desde el presente, aunque no puedo impedir que en mi selección y en mi interpretación escape cierta dosis de idealización y desmitificación del propio Confucio, a partir de las interpretaciones previas que de su obra se han llevado a cabo.

Cuarto, releer a Confucio en nuestro tiempo es posible gracias a la apropiación del propio texto. Nosotros, al igual que otros lectores de su obra en el pasado, hacemos la lectura desde nuestra propia realidad, sin desprendernos de nuestras concepciones paradigmáticas, de nuestra dosis de occidentalización y nuestras aspiraciones individuales y colectivas. Cuando releemos a Confucio lo hacemos desde aquí y desde ahora. Es, por lo tanto, una visión parcial. La valía del texto no se agota en lo que comunica en su sentido original, sino en lo que transmite a nosotros, a nuestro tiempo y a nuestra sociedad.

Shun fue el primer soberano que eligió a su sucesor, Yu, no por sus vínculos de consanguinidad sino por sus méritos. Véase Adler, 2012.

24. Uno de los tantos pasajes en los que Confucio muestra el ideal de esta persona ejemplar que se encuentra en las Analectas es el siguiente: "El maestro dijo: El caballero busca la virtud, el hombre común se apega a la tierra natal. El caballero busca la justicia; el hombre común busca favores" (Analectas, 11:4). 


\section{Lo que el confucianismo puede aportar al proyecto moderno}

Nuestro mundo actual se encuentra en una encrucijada ocasionada en parte por la sensación generalizada del agotamiento del proyecto moderno. Esta sensación se desprende de un comportamiento individualista que ha colocado el beneficio personal por encima del beneficio de la comunidad y que ha privilegiado la lógica del capital sobre otras lógicas. Por lo tanto, si se quieren superar las contradicciones actuales de la modernidad, es preciso encontrar nuevas formas de privilegiar los derechos individuales sin afectar los derechos colectivos y sustentar otras formas de racionalidad económica más allá de la simple acumulación de capital. Para ello, el pensamiento clásico de Confucio proporciona una propuesta concreta para enriquecer la modernidad, superando estas contradicciones, a partir de una visión humanista de la vida y de una aceptación de la responsabilidad comunitaria como elemento fundamental para una sociedad armoniosa.

En primer lugar, las enseñanzas de Confucio tal como han sido recogidas en las Analectas, colocan al ser humano en el centro de sus propuestas. Las preocupaciones de Confucio son plenamente humanas y están encaminadas a proponer un modelo superior de comportamiento en beneficio de toda la comunidad. Un modelo de vida para el aquí y el ahora. Al respecto las Analectas dejan este testimonio: "El Maestro nunca habló de milagros, violencia, desórdenes ni espíritus" (Analectas, 7:21). Confucio planteó con claridad un orden ético para el presente:

\footnotetext{
Zilu preguntó cómo servir a los espíritus y a los dioses. El Maestro respondió: “Tú no eres capaz de servir a los hombres, ¿cómo podrías servir a los espíritus?" Zilu inquirió: “¿Puedo preguntarte sobre la muerte?” El Maestro respondió: “Todavía no conoces la vida, ¿cómo podrías conocer la muerte?” (Analectas, 11:12).
}

La visión humanística de la vida tiene su máxima expresión en el concepto de ren. El ren es el corazón del confucianismo (Wang, 2012). Este concepto ha sido traducido como benevolencia, bondad, virtud o humanidad (Leys, 1998). Etimológicamente, este concepto es escrito con el radical "humano" y el complemento "dos" (仁); o, si uno lo mira así, como un símbolo que podría ser interpretado como ir "más allá" de uno mismo para entablar una relación con los demás (Ching, 1993). Aquella persona que lleva a la práctica el ren es un "hombre bueno", un "hombre virtuoso", un "hombre plenamente humano" 
(Leys, 1998). Al respecto, las Analectas nos dicen: "El Maestro dijo: 'La humanidad es más esencial para la gente que el agua y el fuego. He visto a hombres perder su vida por rendirse al agua o al fuego; nunca he visto a nadie perder su vida por rendirse a la humanidad" (Analectas, 15:35).

La concepción del ren es la perfección de lo que significa ser humano. Originalmente el concepto hacía referencia a la actitud de generosidad de un caballero hacia alguno de sus subalternos, como una expresión de magnanimidad vinculada al origen social de quien la practicaba; pero en las enseñanzas de Confucio ésta se transformó en una virtud universal, lo cual completa —hace perfecto- al ser humano (Ching, 1993). La importancia de esta enseñanza tiene una trascendencia social, ya que el mérito y el carácter ético deberían reemplazar el nacimiento como criterio de un junzi.

Las manifestaciones de una persona distinguida por alcanzar el ren son el ser filial o respetuoso hacia los padres y ancianos (Analectas, 1:2); respetuoso, reverente y leal (Analectas, 13:19); firme, resuelto, frugal y reticente (Analectas, 13:27) y digno de confianza (Analectas, 17:6). En el ideal de Confucio, la persona que sabe que la humanidad es construida, está dispuesta a dar la vida antes de renunciar a ella: "El Maestro dijo: 'Un hombre recto, un hombre que practica la humanidad, no busca la vida a expensas de su humanidad; por el contrario, habrá ocasiones en que dará su vida para realizar su humanidad"' (Analectas, 15:9). El ren es un destino, es una meta. Bajo esta óptica, ninguna persona nace plenamente humana. La humanidad se obtiene con el comportamiento diario hacia uno mismo y se concretiza en el trato hacia los demás.

La esencia de la humanidad consiste en el amor a los otros. "Fan Chi preguntó sobre la humanidad. El Maestro respondió: 'Amar a todos"' (Analectas, 12:22). El amar a todos significa el colocarse en el lugar del otro para relacionarse con él:

El Maestro dijo: "Un caballero no aprueba a una persona por expresar determinada opinión, ni rechaza una opinión por ser expresada por determinada persona”. Zigong preguntó: “ ¿Hay alguna sola palabra que pueda guiarnos toda nuestra vida?” El Maestro respondió: “¿No sería la reciprocidad? Lo que no desees que te hagan a ti, no se lo hagas a los demás” (Analectas, 15:23 y 24).

El amor es entendido como una forma de solidaridad empática con los demás, buscando hacer el bien sin esperar recompensa alguna: 
Yan Hui y Zilu estaban de servicio. El Maestro dijo: “ ¿Y si me manifestarais vuestros deseos íntimos?"

Zilu dijo: "Yo deseo poder compartir mis carros, caballos, túnicas y mantos con mis amigos sin incomodarme si me los estropean".

Yan Hui dijo: "Yo deseo no fanfarronear nunca de mis buenas cualidades ni llamar la atención sobre mis buenas obras".

Zilu dijo: “¿Puedo preguntar cuáles son los deseos íntimos de nuestro Maestro?” El Maestro dijo: "Yo deseo que los ancianos puedan disfrutar de la paz, los amigos disfrutar de la confianza y los jóvenes disfrutar del afecto” (Analectas, 5:26).

El camino para alcanzar el ren es la educación. En las Analectas está escrito: "El Maestro dijo: 'Un caballero no es una vasija"' (Analectas, 2:12). Si cualquier persona puede llegar a ser un caballero por su educación, entonces la capacidad de un ser humano no tiene un límite especifico; un ser humano vale no por su utilidad, que es limitada, sino por su capacidad, que es ilimitada. Desde esta perspectiva, lo importante no es la información especializada ni la capacidad técnica de las personas, sino el desarrollo de la humanidad misma. La educación no está relacionada con tener, sino con ser (Leys, 1998). ${ }^{25}$

Esta idea de que una persona puede ser plenamente humana por medio de la educación, considera, antes que nada, que la educación debe ser un camino de crecimiento interior, de autocultivación, de esfuerzo individual y colectivo por transformarse en una persona mejor. Es la fe en la posibilidad de que los seres humanos somos imperfectos pero mejorables, perfectibles y capaces de aprender, siempre que se lleve a cabo el esfuerzo adecuado ( $\mathrm{Tu}, 1998)$. Y este esfuerzo debe iniciar en el dominio de uno mismo y en el aprendizaje de los ritos, los cuales son considerados la manifestación material del orden social:

Yan Hui preguntó acerca de la humanidad. El Maestro respondió: "La práctica de la humanidad se reduce a domesticar el yo y a restaurar los ritos. Domestica el yo y restaura los ritos, aunque sea un solo día, y el mundo entero se unirá a tu humanidad. La práctica de esta virtud procede del yo, no de ninguna otra cosa" (Analectas, 12:1).

25. En este sentido, tradicionalmente se concibió que los clásicos, incluyendo las Analectas, no eran libro para aprenderse sino para ser vividos. Su conocimiento no buscaba la especulación filosófica, sino la vivencia práctica de los mismos (Fung, 1997). En la tradición confucionista los valores abstractos se materializaban en relaciones sociales concretas (Tamney y Chiang, 2002). 
La educación se convierte así en el medio de igualdad y de respeto a la individualidad de cada ser humano. Confucio plantea así una especie de igualdad natural entre todos los hombres en términos de su capacidad para aprender; aunque existen diferencias entre las personas, éstas provienen de cómo estas capacidades son empleadas y qué tan deseoso está cada uno para poner en práctica lo aprendido (Cheng, A., 2011).

Desde mi perspectiva, el punto fundamental de la conceptualización del ren en la propuesta confuciana es que se convierte en un ideal humano que permite sintetizar las dinámicas tradicionalmente opuestas entre las aspiraciones individuales y las demandas colectivas. Si bien es cierto, la lectura del pensamiento confuciano durante siglos privilegió el aspecto colectivo de las relaciones personales, encerrándolas en una serie de ritos, prácticas y costumbres sobre el deber ser, justificando un orden social jerárquico que imponía la sumisión como forma de control político y social desde una visión patriarcal de la sociedad, en los orígenes del pensamiento confuciano destaca la libertad de decisión para desarrollar el ren. La materialización exterior del ren, a partir de las demás virtudes, sólo es posible después de una decisión individual, personal, íntima.

En efecto, conforme a las enseñanzas consagradas en las Analectas, la realización del ren no se logra en la individualidad. La práctica del ren consiste en la consideración de los otros (Fung, 1997). Es a partir de la convivencia con los otros, guiada por una serie de virtudes, como se puede conseguir la humanidad plena. Y los otros son el género humano, no solamente el círculo ensalzado por la ideología imperial sobre las cinco relaciones jerárquicas: padre-hijo, soberano-gobernado, esposo-esposa, hermano mayor-hermano menor y amigo-amigo. ${ }^{26} \mathrm{El} \mathrm{junzi} \mathrm{tiene} \mathrm{una} \mathrm{perspectiva} \mathrm{más} \mathrm{amplia} \mathrm{de} \mathrm{las}$ relaciones recíprocas que debían establecerse en sociedad:

Sima Niu se lamentaba: "Todos tienen hermanos; yo soy el único que no tiene". Zixia contestó: "Yo he oído decir que la vida y la muerte son decretadas por el destino, que las riquezas y los honores son otorgadas por el Cielo. Puesto que un

26. Al respecto, Wei-Ming Tu observa que si bien es cierto que la piedad filial fue considerada el primer paso hacia la excelencia moral, Confucio al parecer consideraba que la mejor manera de preservar la dignidad personal y la identidad era no alinearnos nosotros mismos a la familia, sino cultivar nuestros verdaderos sentimientos hacia nuestros padres; para poder encarnar la familia en nuestras mentes y corazones es preciso permitirnos ir más allá del egocentrismo, transformando el yo privado y cerrado en una autorrepresentación abierta (Tu, 1998). 
caballero se comporta con reverencia y diligencia, trata a los demás con deferencia y cortesía, todos los que se hallan dentro de los Cuatro Mares son sus hermanos. ¿Cómo podría un caballero quejarse de no tener hermanos?” (Analectas, 12:5).

\section{Consideraciones finales}

A lo largo de este artículo he argumentado sobre la necesidad de que la modernidad incorpore tradiciones no occidentales a su proyecto, con la intención de que éste pueda alcanzar una dimensión auténticamente universal. Esto significa, evidentemente, la necesidad de superar la tensión entre lo universal y lo particular, lo cual puede ocurrir en la medida en que reconozcamos que la globalización abre la posibilidad de un diálogo fecundo desde las condiciones particulares de las localidades, siempre que estemos dispuestos a considerar nuestros paradigmas como un punto de arranque para la comprensión de nuestra realidad y jamás como el punto final, como la última palabra de una historia que escribimos colectivamente. Exige de nuestra parte un esfuerzo intelectual honesto para superar la dicotomía Oriente/Occidente, a partir de reconocer con humildad que nuestra civilización no tiene las únicas respuestas posibles a las interrogantes del mundo de hoy, ni que la ciencia y su instrumentalización nos pueden proporcionar todas las seguridades y certezas que antes pensamos.

La riqueza de las comunidades humanas, sus expresiones, sus cosmovisiones y sus experiencias nunca son posibilidades cerradas a sus propios contextos históricos en las que surgen. Las percepciones que tenemos de estas comunidades es lo que hace que sean para nosotros posibilidades de encuentro o de negación, de aprendizaje o de rechazo. En cada cultura y en cada civilización podemos descubrir elementos de unión para complementar nuestros saberes y para encontrar soluciones a nuestros problemas. Esto es particularmente significativo en cuanto a las posibilidades de proponer, desde el confucianismo despojado de cualquier tinte ideológico del contexto histórico y cultural de que se originó, algunos principios orientadores que nos permitan reconocer rutas alternas para superar las contradicciones actuales de la modernidad.

Evidentemente, la selección del texto de las Analectas representa ya en sí misma una ideología implícita. No sólo por dejar a un lado otros textos del canon confuciano, sino también porque el texto de las Analectas como unidad es también producto de una interpretación ideológica en la recopi- 
lación selectiva y arbitraria del pensamiento original atribuido a Confucio. Sin negar esta limitación de origen, la propuesta de este artículo es mirar las Analectas desde el presente y nuestro propio contexto histórico y cultural para encontrar algunas claves que limitan la modernidad eurocentrista, para abrir nuevos caminos interpretativos que permitan transitar hacia un proyecto más amplio y plural.

Específicamente, de este confucianismo podemos retomar la idea de una humanidad construida con nuestros actos, una humanidad que es universal, una humanidad que no se nos otorga de manera perfecta y plena por nacimiento, sino que complementamos con nuestras acciones ordinarias. Una humanidad que necesita de los otros para que pueda ser completada. Una humanidad que se realiza en la medida en que nos preocupemos genuinamente por los demás. Una humanidad que nos lleve a comprender que más allá de nuestras diferencias, constituimos una sola familia. Y una humanidad que debe empezar desde el esfuerzo propio, constante, particular. Una idea de humanidad que no se plantea ni como un gran relato más ni como una utopía, sino como una posibilidad próxima cuando, cada uno de nosotros, en un acto de libertad y conciencia, apostamos por ser mejores personas desde la educación. Una educación, cabe decir, cuyo eje central debe ser la humanidad misma.

La idea de una humanidad construida a partir de las decisiones personales que nos lleven a relacionarnos empáticamente con los demás, son principios que pueden sentar las bases para que la sociedad china se salve a sí misma de sus profundas y actuales contradicciones. Pero esta salvación no es exclusiva para el mundo chino, al mismo tiempo puede contribuir a superar las contradicciones de nuestro mundo moderno: de lo contrario no habrá un futuro plenamente humano, ni para China ni para el resto del mundo.

\section{Referencias bibliográficas}

Adler, Joseph A. (2011), "Confucionism in China Today”, Pearson Living Religion Forum. Disponible en: http://www2.kenyon.edu/Depts/Religion/ Fac/Adler/Writings/Confucianism\%20Today.pdf

- - (2012), Chinese Religions, Nueva York: Routdlege.

Berman, Marshall (1998), Todo lo sólido se desvanece en el aire: La experiencia de la Modernidad, México, DF: Siglo XXI Editores. 
Botton, Flora (2000), China: Su historia y cultura hasta 1800, México, DF: El Colegio de México.

Callinicos, Alex (1993), Contra el posmodernismo: Una crítica marxista, Bogotá: El Áncora Editores.

Casullo, Nicolás (1995), "Modernidad, biografía del ensueño y de la crisis", en Casullo, Nicolás, El debate Modernidad Posmodernidad, Buenos Aires: El Cielo por Asalto, pp. 9-63.

Cheng, Anne (2011), "Virtue and Politics: Some conceptions of sovereignty in Ancient China", Journal of Chinese Philosophy, núm. 38, pp. 113-145.

Cheng, Chung-Ying (2011), "New Confucianism as a Philosophy of Humanity and Governance", Journal of Chinese Philosophy, núm. 38, pp. 1 y 2.

Ching, Julia (1993), Chinese Religions, Nueva York: Orbis Books.

Ching-sze Wang, Jessica (2007), John Dewey in China: To Teach to Learn, Nueva York: State University of New York.

Confucio (1997), Analectas (traducción, edición y notas A. Suárez), Madrid: Kairós.

Coppola, Carlo (1999), "Lu Xu”, en Riggs, Thomas (ed.), Reference Guide to Short Fiction, Detroit: James Press, pp. 387 y 388.

Córdova, Marycela (2000), "Modernidad, cultura y devenir del mundo actual", en Zaraoui, Zidane (ed), Modernidad y Posmodernidad: La crisis de los paradigmas y los valores, México, DF: Limusa, pp. 135-159.

Corsi, Elisabetta (2001), Grandes obras de la literatura china, México, DF: Universidad Nacional Autónoma de México.

De Bary, William T. (1998), "Introduction", en De Bary William T., y Weiming, Tu (eds.), Confucianism and Human Rights, Nueva York: Columbia University Press, pp. 1-26.

Ellis, Elisabeth (2005), "Modernity: Overview", en Horowitz, Maryanne Cline, New Dictionary of History of Ideas, Detroit: Charles Scribner's Sons, pp. 1473-1475.

Enciclopedia Británica (2014), “Donglin”, Encyclopaedia Britannica, obtenido de: http://0-www.britannica.com.millenium.itesm.mx/EBchecked/topic/609021/Donglin

Encyclopedia of World Biography (2004), "Ch'en Tu-hsiu", Encyclopedia of World Biography, vol. 3, Detroit: Gale, pp. 501 y 502.

Eno, Robert (2012), "Introduction", Analects, disponible en http://www. indiana.edu/ p374/analects_of_confucius_(eno-2012).pdf 
Fairbank, John K. (1992), China: A New History, Cambridge: The Belknap Press of Harvard University Press.

Fung, Yu-lan (1997), A short history of Chinese Philosophy, Nueva York: Free Press.

Giddens, Anthony (1996), Consecuencias de la Modernidad, Madrid: Alianza Universidad.

Gu, Ming (2010), “Everyone's Confucius, all Reader's Analects”, Journal of Chinese Philosophy, 37(1), pp. 34-47.

Habermas, Jürgen (1995), “Modernidad, un proyecto incompleto", en Casullo, Nicolás, El debate Modernidad Posmodernidad, Buenos Aires: El Cielo por Asalto, pp. 131-144.

Hang, Lin (2011), "Traditional Confucianism and its Contemporary Relevance", Asian Philosophy, 21(4), pp. 437-445.

Hsia, Maria H. (2001), Return of Dragon: China's Wounded Nationalism, Boulder, Colorado: Westview Press.

Huang, Su-Jen (1994), “The Religion of China: An interpretation”, Journal of the History of the Behavioral Sciences, 30(1), pp. 3-18.

Jacobs, Andrew (abril 22, 2011), "Confucius Statue Vanishes Near Tinananmen Square”, The New York Times, International, disponible en: http:// www.nytimes.com/2011/04/23/world/asia/23confucius.html

Khondker, Habibul H. (2004), "Glocalization as Globalization: Evolution of a Sociological Concept”, Bangladesh e-journal of Socology, 1(2), pp. 1-9.

Le Goff, Jaques (1997), Pensar la historia: Modernidad, presente, progreso, Barcelona: Paidós.

Leys, Simon (1998), Confucio: Analectas, versión y notas, Madrid: EDAF.

López, Víctor (2012), La Modernidad de China: Fin del socialismo y desafíos de la sociedad de mercado, México, DF: Siglo XXI Editores.

Luhmann, Niklas (1997), Observaciones de la Modernidad: Racionalidad y contingencia en la sociedad moderna, Barcelona: Paidós.

Marín-Ardila, Luis F. (2009), "La modernidad como imaginario: La excepcionalidad de Europa o la modernidad como geografía y experiencia histórica de Europa", Pensamiento y Cultura, 12(2), pp. 243-261.

Martin, Jaques (2009), When China Rules the World: The End of the Western World and the Birth of a New Global Era, Nueva York: The Penguin Press.

Mitter, Rana (2008), Modern China: A very short History, Oxford: Oxford University Press. 
Pagden, Anthony (1995), Señores de todo el mundo. Ideologías del Imperio en España, Inglaterra y Francia en los siglos XVI, XVII y XVII, Barcelona: Ediciones Península.

Paradise, James F. (2009). "China and International Harmony: The Role of Confucius Institutes in Bolstering Beijing's Soft Power”, Asian Survey, 49(4), pp. 647-669.

Peerenboom, Randall (1998), "Confucian Harmony and Freedom of Thought", en De Bary William T., y Weiming, Tu (eds.), Confucianism and Human Rights, Nueva York: Columbia University Press, pp. 234-260.

Robertson, Ronald (1992), Globalization: Social Theory and Global Culture, Londres: Sage.

Sardar, Ziauddin (2004), Extraño Oriente: Historia de un prejuicio, Barcelona: Gedisa.

Slingerland, Edwards (2008), "Classical Confucianism: Confucius and the Lu-Yün”, en Mou, Bo, (ed.), History of Chinese Philosophy, Nueva York: Routledge.

Smart, Ninian (1989), The World's Religions, Oxford: Oxford University Press. Tamney, Joseph B., y Chiang, Linda H. (2002), Modernization, Globalization and Confucianism in Chinese Societies, Westport: Praeger Publishers.

Touraine, Alain (2002), Crítica a la Modernidad, México, DF: Fondo de Cultura Económica.

Tu, Weiming (1998), “Confucius and Confucianism”, en Slote, Walter H., y Devos, George A. (eds.), Confucianism and the Family, Nueva York: SUNY Press, pp. 3-36.

Viano, Carlo A. (1995), "Los paradigmas de la modernidad", en Casullo, Nicolás, El debate Modernidad Posmodernidad, Buenos Aires: El Cielo por Asalto, pp. 175-193.

Wallerstein, Immanuel (2007), Universalismo europeo: El discurso del poder, México, DF: Siglo XXI Editores.

Wang, Huaiyu (2012), "Ren and gantong: Openness of heart and root of Confucianism”, Philosophy East \& West, 62(4), pp. 463-504.

Xueying. Zhang, y Xin, Xin (2008), "Huellas de treinta años de reforma y apertura", China Hoy, núm. 12, disponible en: http://www.chinatoday. com.cn/hoy/2008n/s2008n12/p12.htm

Yao, Xinzhong (2012), "Introduction: Conceptualizing virtues in the Analects of Confucius”, Journal of Chinese Philosophy, 39(1), pp. 3-7. 
Zhang, Tong, y Schwartz, Barry (1997), "Confucius and the Cultural Revolution: A Study in Collective Memory", International Journal of Politics, Culture and Society, 11(2), pp. 189-211. 